\title{
SELECTION OF DRAINS COVERINGS TYPE IN EASTERN OF EGYPT
}

\author{
Shaimaa M. Khiry ${ }^{1}$, Magdy H. Mowfy ${ }^{2}$, Walaa Y. El-Nashar ${ }^{3}$ \\ ${ }^{1}$ Civil Engineer in Drainage Projects Organization for East Delta, Ministry of Public Works and Water Resources, \\ Zagazig, El-Sharkia, Egypt \\ ${ }^{2}$ Water Engineering and Water Structure Engineering Department, Faculty of Engineering, Zagazig University, Zagazig, \\ El-Sharkia, Egypt \\ ${ }^{3}$ Water Engineering and Water Structure Engineering Department, Faculty of Engineering, Zagazig University, Zagazig, \\ El-Sharkia, Egypt
}

\begin{abstract}
Drainage affects a host of biophysical soil properties and strongly influences crop growth and quality. Drainage systems improve field operations, enhance growing conditions for crop production and increase crop yields on poorly drained soils. Coverings are used to pass the small discharge to function as bridge there are two types for coverings, pipe or box type. The protection of agricultural drains against pollution resulting from illegal dumping of both liquid and solid waste in residential areas can be achieved in different ways. The main problems which lead to a perceived need to cover a drain are: to minimize the adverse impact of a polluted drain, especially close to residential areas, need to use the land area occupied by the drain for an access road or some other use, poor soil stability leading to bank failure, and to protect them from pollution. The negative impact is the high cost, difficulty of finding an alternative route and encroachment of residential areas to the new drain sites as a result of population growth. The concrete pipes or box sections are used for drains coverings. In this study twenty drains coverings are selected and redesign them as pipe type, under pressure and under gravity flow by using Hazen-Williams equation and as a box type, under gravity flow by using Manning equation. Hydraulic study is done. The comparison for heading up losses, area and hydraulic radius is covered. Economic studies are done also to evaluate these coverings. The best alternative for each covering is chosen in the hydraulic point, the economic point and the both hydraulic and economic points.
\end{abstract}

Keywords: Drain Covering; Pipe Type; Box Type; Under Pressure Flow; Under Gravity Flow and Egypt.

\section{INTRODUCTION}

The covering is closed canal or industrial type (culvert). It is created to pass the discharge of waterway under the road or railway line. The protection of agricultural drains against pollution resulting from illegal dumping of both liquid and solid wastes in residential areas can be achieved in different ways. There are a lot of researches about this topic such as Christodoulou [1] studied the losses at drop manholes in supercritical pipelines. He found that the local head-loss coefficient was governed by a dimensional drop parameter, expressed in terms of the drop height and the inflow velocity. Dasika [2] investigated the two equations for rate of flow under inlet control by experiment. His study also recommended that the tail water depth be equal to the diameter of the pipe using a baffle wall. Clarht and Charles [3] did a model to simulate a model for the flow of a slowlysettling suspension being transported in the laminar regime through a pipeline with a constant overall pressure drop by using experimental scaled-down pipeline data. Ferro [4] reported the results of an investigation carried out to test the applicability of the self-similarity hypothesis for determining the flow-resistance law in small-diameter plastic pipes. Hager and Guidice [5] derived dimensionless equations of culvert flows for basic flow types: critical, uniform, gated, and pressurized flows. Bombardelli and Garcia [6] used the Hazen-Williams formula for the design of large-diameter pipes, without regarding for its limited range of applicability. Brasington and Smart [7] investigated the evolution and dynamics of larger-scale landforms. Lee and Jin [8] developed a computer program for the design of rectangular culverts, which needs a number of iterations for achieving a solution. Tao and Xiyun [9] examined the effectiveness of the approach for predicting the migration of drops in a shear flow and investigated the behavior of the drop migration in the channel flow under zero gravity. American Association of State Highway and Transportation Officials [10] recommended the concept of critical storm duration to estimate a design flood discharge for culvert design. Wood [11] studied the traditional approach to transient analysis might dispute the claim. Ku and Jun [12] made a computer program that considered nonuniform characteristics of the flow in the culvert by widely adopting new information. Kang et al. [13] recommended the concept of critical storm duration to be appropriate to estimate a design flood discharge for culvert design. Korea Expressway Corporation [14] described hydraulic design procedures for culverts. Fahmy [15] studied the covering of canals and drains, advantages and disadvantages. Vatankhah and Easa [16] used the Manning formula and the attractive force equation as 
governing equations to design erodible and riprap channels. Colin, Catherine and Fabre [17] experimented on vertical turbulent flow with mill metric bubbles, under three gravity conditions, upward, downward and microgravity flows. Yoo and Lee [18] determined dimensions of a rectangular culvert section, current design approaches by using several trial calculations.

The main objective of this study is evaluating the drains coverings in Egypt according to the hydraulic and economic points. Twenty drains coverings are selected from the field then the three alternatives are suggested as pipe type with under pressure flow, pipe type with under gravity flow and box type with under gravity flow. Then the best alternative is chosen according to hydraulic and economic points.

\section{STUDY AREA}

The study area is located in El-Sharkiya which is in the East Delta as shown in Fig-1, the area of East Delta is about $2,163,331$ feddan and lies between $30^{\circ} \mathrm{N}$ to $31^{\circ} 30^{\prime} \mathrm{N}$ and $31^{\circ}$ $6^{\prime} \mathrm{E}$ to $32^{\circ} 20^{\prime} \mathrm{E}$. In this study, the areas which studied are located in Zagazig, Minya El-Kamh, Diarb Negm, Mashtol ElSook, Kafr Saker, Billbis and Abu Kebir cities.

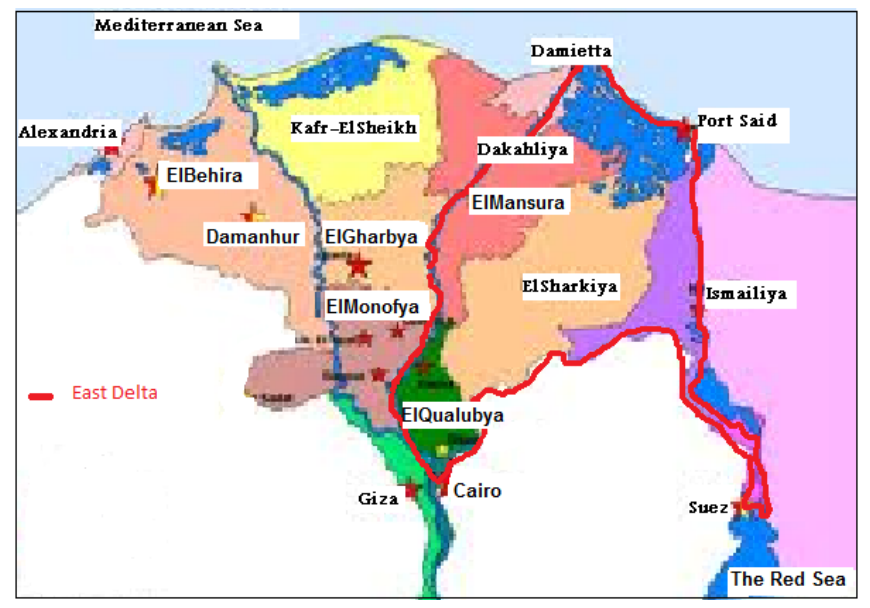

Fig-1: Location Map of the Study area

\section{METHODOLOGY}

The Methodology of this paper is:

1- Collecting the data of selected twenty drains coverings, this data is collected from the field and ministry of water resources and irrigation.

2- The hydraulic evaluation includes hydraulic design and calculation of heading up losses, area of cross section, hydraulic radius and velocity for pipe type with under pressure and under gravity flow by using Hazen-Williams equation and for box type with under gravity flow by using Manning equation.
3- The economic evaluation includes the calculation of the cost of covering for each alternative if it was constructed in the past or if it will be constructed in year 2013 .

4- The best alternative is chosen according to the hydraulic and economic evaluations.

\section{HYDRAULIC EVALUATION}

In general, the design of a waterway covering requires a hydraulic design. The modular design will therefore be related to the design principles and calculations only. The following items are necessary when designing a waterway covering, for both the pipe and box types:

1. Precise definition of the characteristics of the covered reach, passing flow and the corresponding water levels;

2. Definition of the appropriate features of the vents of the covering as box dimensions or pipe diameter and the number of vents;

3. Computing the generated heading up losses due to the inlet, friction, elbow, bend, manholes, and the exit structure along the covering path;

4. Defining the setting levels of the upstream and downstream bottom invert levels. Subsequently the levels of the upper ones can be easily determined;

5. Defining the generated upstream and downstream water levels;

6. Checking the effects of the covering construction on the upstream waterway reach.

\subsection{Design Criteria for Drain Covering}

The Design requires extensive data collection and field survey procedures including the following parameters:

* Drain catchment area;

* Longitudinal profile of the drain;

* Drain characteristics;

* The expected flow rate;

* Soil characteristics;

* The location of the drain in relation to a potential solid waste management facility;

* Information on the expected use of the area above the covered drain.

This data of selected twenty drains coverings is collected from the field and ministry of water resources and irrigation

\subsection{The Dimensional Analysis}

Dimensional analysis is used to obtain dimensionless parameters, which correlate between the headings up losses variables. The main variables affected the heading up losses in the present work are as follows:
1 -
Q: Discharge $\left(\mathrm{L}^{3} \mathrm{~T}^{-1}\right)$;
2- $\quad \mathrm{V}$ : the velocity of drain water $\left(\mathrm{L} \mathrm{T}^{-1}\right)$;
3- HL: Heading up losses (L);
4- $\quad$ D: the diameter of pipe (L);
5- $\quad \mathrm{L}_{\mathrm{c}}$ : Covering length (L); 
$\begin{array}{ll}\text { 6- } & \text { R: Hydraulic radius }(\mathrm{L}) \\ \text { 7- } & \text { A: } \operatorname{area}\left(\mathrm{L}^{2}\right)\end{array}$

Applying the Buckingham's theorem ( $\pi-$ theorem) [19]:

$$
\begin{aligned}
& H L=f\left\{Q, D, L_{c}, V, R, A\right\} \ldots . . \\
& 0=f^{\prime}\left\{H L, Q, D, L_{c}, V, R, A\right\} .
\end{aligned}
$$

$\mathrm{D}$ and $\mathrm{Q}$ are taking as the repeating variables.

The final equation which correlates between the variables used to obtain dimensionless parameter as follows:

$\Phi\left[\mathrm{HL} / \mathrm{L}_{\mathrm{c}}, \mathrm{HL} / \mathrm{R}, \mathrm{D}^{2} \mathrm{~V} / \mathrm{Q}, \mathrm{R} / \mathrm{L}_{\mathrm{c}}\right.$, and HLD/A $]=0$.

\subsection{Drain Covering Options}

\subsubsection{Pipe Type}

This type, which can have one or more vents, is more suitable for waterways with a small discharge. Pipes should be constructed from pre-cast reinforced concrete. The length of the pre-cast units will depend on the pipe diameter and the specification of the reinforcement used. Design of the covering is as a pipe type according to under pressure and under gravity flows is given as follows:

\subsubsection{Pipe with under Pressure Flow}

By using Hazen-Williams equation as follow [20]:

$$
\begin{aligned}
& \mathrm{V}=\mathrm{K} * \mathrm{C} * \mathrm{R}^{0.63} * S^{0.54} . \\
& \mathrm{Q}=\mathrm{A} * \mathrm{~V} \ldots \ldots \ldots \ldots \ldots
\end{aligned}
$$

Where,

V: Velocity of covering water by Hazen-William equation;

$\mathrm{K}$ : Conversion factor $=0.849$;

C: Pipe roughness coefficient (dimensionless) $=140$;

R: Hydraulic radius $=\mathrm{A} / \mathrm{P}$;

A: Cross-sec area of covering $=\frac{\pi D^{2}}{4}$ for under pressure flow;

P: Wetted Perimeter;

$Q$ : Flow rate in $\mathrm{m}^{3} / \mathrm{s}$;

$S$ : Slope of hydraulic grade line, dimensionless by HazenWilliam equation;

$$
S=\frac{10.67 * Q^{1.85}}{C^{1.85 * D^{4.87}}}
$$

Where,

$D$ : Diameter of pipe (m).
To calculate the total heading up losses (HL) according Hazen-William equation as following [21]:

$$
\mathrm{HL}_{\text {total }}=\mathrm{h}_{\mathrm{sc}}+\mathrm{h}_{\mathrm{en}}+\mathrm{h}_{\mathrm{f}}+\mathrm{h}_{\mathrm{ex}}
$$

Where;

$\mathrm{HL}_{\text {total }}$ : Total heading up losses (m);

$\mathrm{h}_{\mathrm{sc}}$ : Heading up losses due to network grasses (m);

$\mathrm{h}_{\mathrm{en}}$ : Heading up losses due to entrance $(\mathrm{m})$;

$\mathrm{h}_{\mathrm{f}}$ : Heading up losses due to friction (m);

$\mathrm{h}_{\mathrm{ex}}$ : Heading up losses due to exit (m);

$$
\boldsymbol{h}_{s c}=C_{s c} * \frac{V^{2}}{2 * g}[21]
$$

Where;

$g$ : Gravity acceleration;

$C_{s c}:$ Factor of screen $=\mathrm{B}(\mathrm{t} / \mathrm{b})^{4 / 3} * \sin \alpha$;

Where;

B: Dimensionless coefficient depends on the shape of straps $=2.42$;

$\mathrm{t}$ : Thickness of wicker straps for grille $=0.02$;

b: Distance between the wicker $=0.15$;

$\alpha$ : Slop angle of grille $=60$;

$$
h_{e n}=C_{e n} * \frac{V^{2}}{2 * g}[21]
$$

Where;

$C_{e n}$ : Coefficient depends on the shape of entrance $=0.2$;

$$
\mathrm{h}_{\mathrm{f}}=S^{*} L[21]
$$

$L$ : Length of covering (m);

$$
h_{e x}=C_{e x} * \frac{V_{c}^{2}}{2 * g}[21]
$$

Where;

$\mathrm{C}_{\mathrm{ex}}$ : Coefficient depends on the shape of exit=1.0;

\subsubsection{Pipe with under Gravity Flow}

By using Hazen-Williams equation as in equation (4), (5) \& (6), but the area and wetted perimeter of water are calculated as depth of water is 0.667 of the diameter of the pipe (D) as shown in Fig-2. The total headings up losses are calculated as equations (7) to (11). 


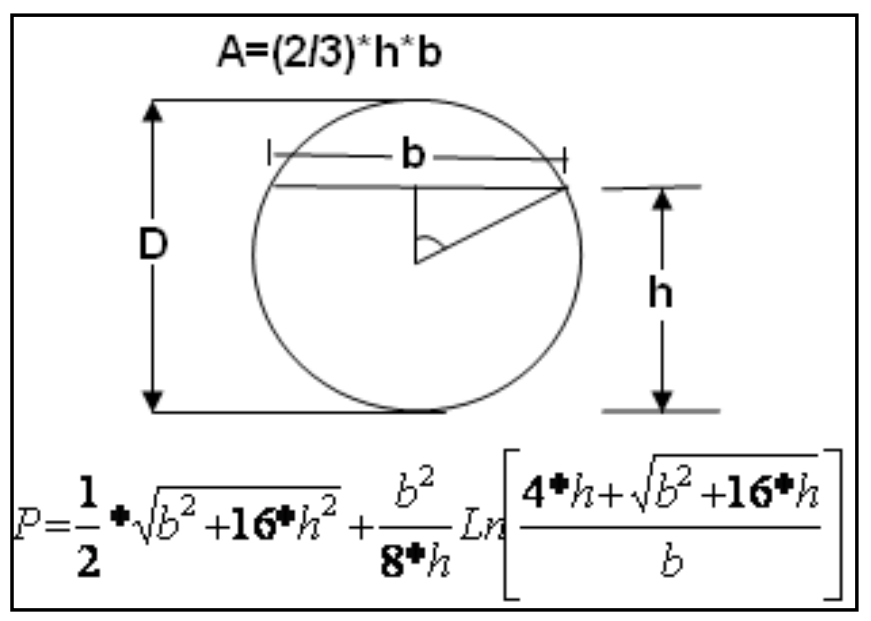

Fig-2: Calculation of the Area and Wetted Perimeter in Pipe with under Gravity Flow

\subsubsection{Box Type}

In this type, the cross section of the vent can be rectangular or square and can have one or more vents. Box section covering is appreciably more costly than the pipe. It has the benefit that it is more suitable for higher flow rates, although the cost per square meter of cross section is still higher than for pipes. It is also stronger, being constructed from reinforced concrete, and therefore more suitable if the covered area is expected to be subjected to heavy loading, for example if it is to be used as a road.

To design the box type with under gravity flow, Manning equation is used as follow [22]:

$$
Q=\frac{1}{n} * A * R^{2 / 3} * S^{0.5}
$$

Where,

$n$ : Coefficient of roughness for concrete $=0.015$ (dimensionless);

$A$ : Area of water in the cross section $=\mathrm{w}^{*} \mathrm{y}\left(\mathrm{m}^{2}\right)$;

$w$ : Width of the box cross section $(\mathrm{m})$;

$y$ : Depth of water $(\mathrm{m})$;

$V$ : Velocity of flow in the box covering $(\mathrm{m} / \mathrm{sec})$;

$R$ : Hydraulic radius $=\mathrm{A} / \mathrm{P}(\mathrm{m})$;

$\mathrm{P}$ : Wetted perimeter $=w+2 y(\mathrm{~m})$;

$S$ : Slope of water in the covering.

Heading up losses ( $\left.\mathrm{HL}_{\mathrm{total}}\right)$ for box type are as equation (7), $h_{s c}, h_{e n}$, and $h_{e x}$ as are in equations (8), (9) and (11) $h_{f}$ is calculated from Manning equation as following:

$$
\boldsymbol{h}_{f}=\boldsymbol{L}\left(\frac{Q * n}{A * \boldsymbol{R}^{2 / 3}}\right)^{2}
$$

\section{ECONOMIC EVALUATION}

This part presents the economic evaluation of the covering for different drains. The old costs and costs in year 2013 for the redesign as pipe with under pressure and under gravity flow and box type with under gravity flow. The saving money for the two alternatives is calculated. This saving is calculated for different covering which were constructed in the past if it was constructed by the redesign, and if it will be constructed in year 2013 as flowing:

\subsection{Calculation of the Inflation Rate (i)}

The cost of construction of the covering is available in the year which each covering was constructed, to calculate the saving of money if this covering was constructed by the redesign in the past the prices for each diameter in each year must be known. The price of the actual diameter and the price of the same diameter in year 2013 are available, and the inflation rate can be calculated. By using this inflation rate for each year, the price for any new diameter can be calculated, and then the prices for new diameters can be calculated. To calculate inflation rate, the following equation is used [23].

$$
\mathrm{F}=\mathrm{P}(1+\mathrm{i})^{\mathrm{N}}
$$

Where,

$\mathrm{F}$ : the future worth;

P: the present worth "principal";

i: inflation rate $(\%)$;

$\mathrm{N}$ : number of years;

\subsection{Money Saving in the Past and in Year 2013}

Saving of money for redesigned coverings is calculated if the drains coverings were constructed in the past and if the drain coverings will be constructed in year 2013 .

\section{RESULTS AND DISCUSSION}

The results include the hydraulic results and economic results. The selection of covering is chosen according hydraulic point and according economic. The final choice of covering is according to the both of hydraulic and economic points.

\subsection{Hydraulic Results and Discussion}

1- For heading up, the best design for all selected drain coverings is the pipe type with under gravity flow. The values of (HL) for the selected twenty drains coverings are shown in Chart-1. From this chart, the values of heading up are different according to the length of covering, when the length of covering increases, the heading up increases and vice versa. 


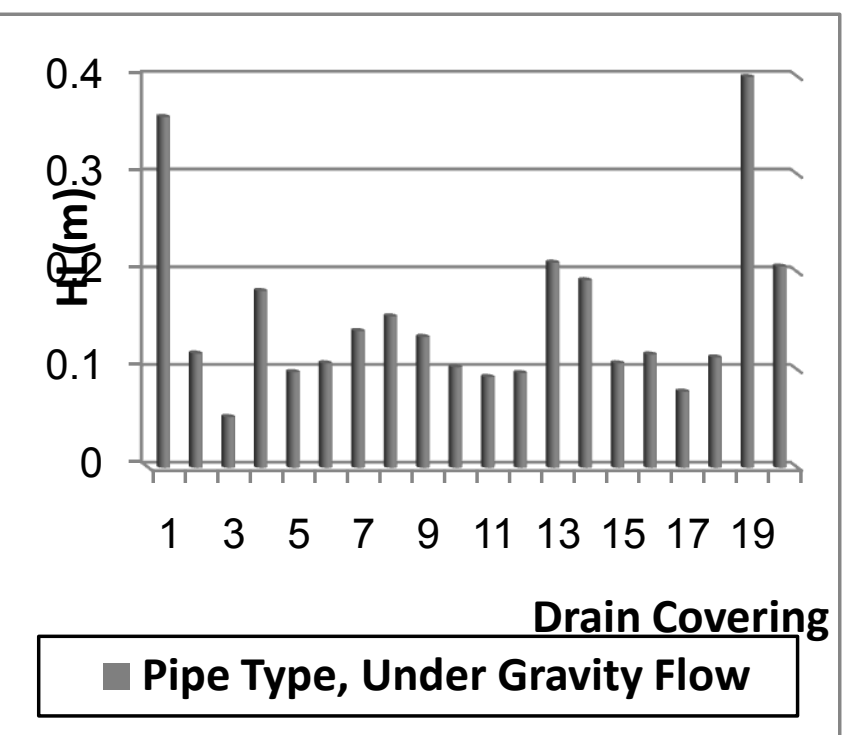

Chart-1: The Values of (HL) for Selected Drains Coverings

2- For all drains (from 1 to 20), it's found that the lowest value of diameter (D) is resulted from the case of pipe type with under pressure flow. The values of (D) are shown in Chart-2.

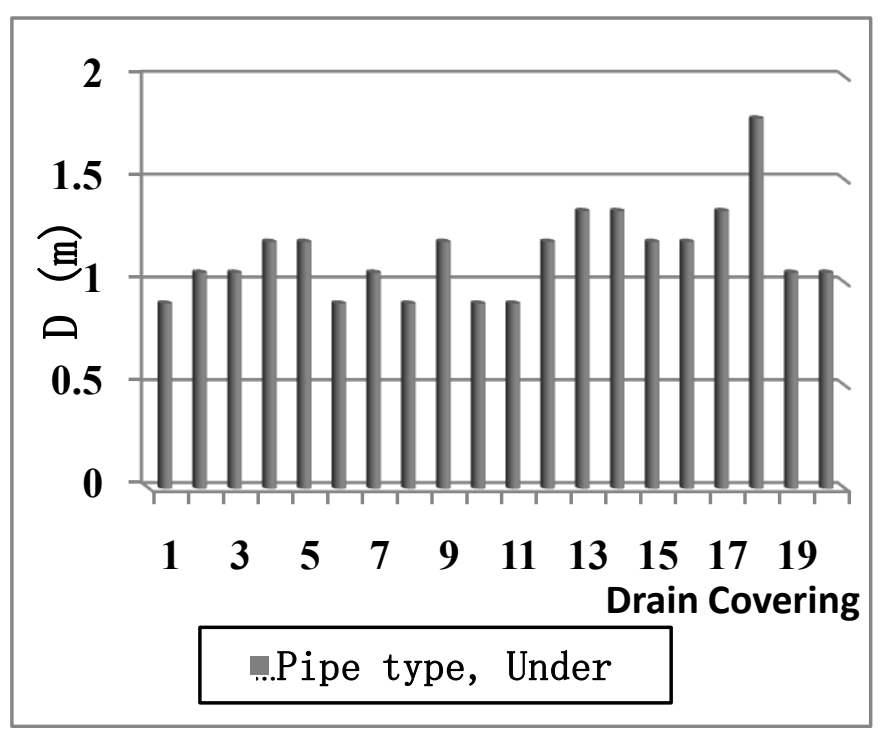

Chart-2: The Values of (D) for Selected Drains Coverings

3- For drains (from 1 to 17), it's found that the lowest value of area (A) is resulted from case box type with under gravity flow. For drains (from 18 to 20), it's found that the lowest value of area (A) is resulted from case pipe type and under gravity flow. The values of (A) are shown in Chart-3.

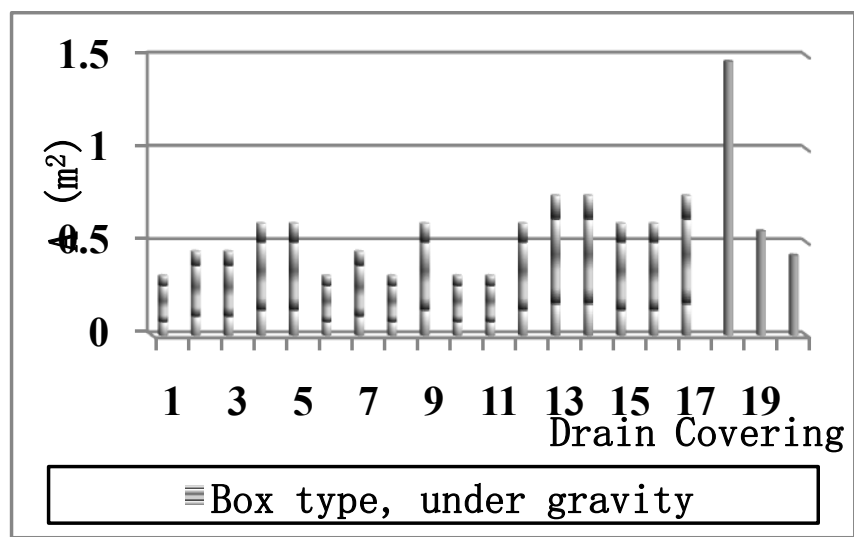

Chart-3: The Values of (A) for Selected Drains Coverings

4- For drains (from 1 to 17 ) it's found that the lowest value of hydraulic radius ( $\mathrm{R})$ is resulted from case box type with under gravity flow. For drains (from 18 to 20), it's found that the lowest value of hydraulic radius $(\mathrm{R})$ is resulted from case pipe type and under gravity flow. The values of (R) are shown in Chart-4.

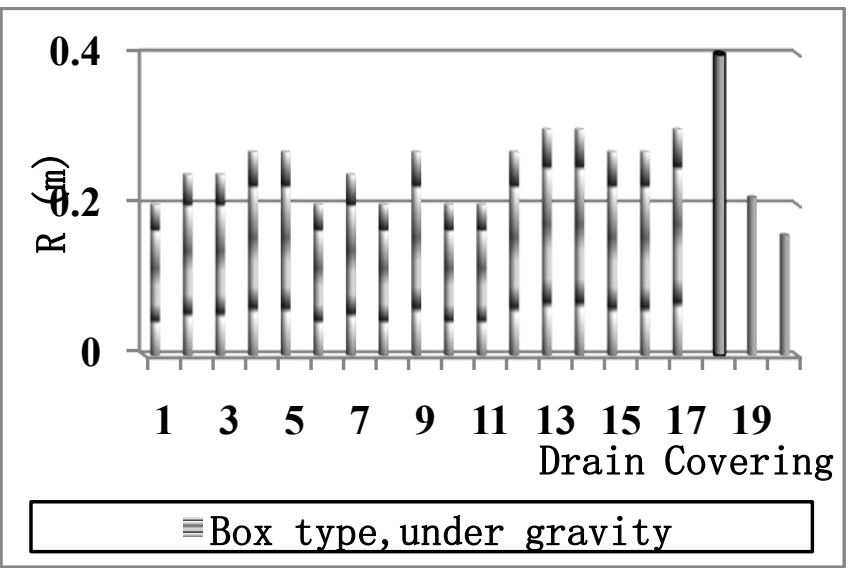

Chart-4: The Values of (R) for Selected Drains Coverings

5- The values of (V) for all drains (from 1 to 20), it's found that in the velocity is in the range for all types.

6- For drains (from 1 to 18), it's found that the lowest value of heading up (HL) is resulted from case of pipe type with under gravity flow, but their areas are large values. So, the best choice is pipe type, under gravity flow, because in this type it is found that the lowest value of area and hydraulic radius and the heading up losses values are low also. The difference between the values of (HL) between box type from pipe under pressure flow and pipe type, under gravity flow is small values.

7- For drains (19 and 20) it's found that the lowest value of (HL) is resulted from box type from pipe under pressure flow, but the value of area is large for the same type. So, the best choice is resulted from case pipe type, under pressure flow. 
8- From the previous charts, the best choice due to the heading losses, velocity and discharge is the pipe type with under gravity flow but according to area and hydraulic radius is pipe type with under pressure flow. The best choice for drains (from 1 to 18) is pipe type with under gravity flow, but for drains 19 and 20 is pipe with under pressure flow.

\subsubsection{Design Curves according to Hydraulic Results}

\subsubsection{Design Curves for Pipe Type under Pressure}

Flow:

The relation between the discharge $\left(\mathrm{Q}\left(\mathrm{m}^{3} / \mathrm{sec}\right)\right)$ and the length of covering over its diameter ( $\mathrm{L} / \mathrm{D}$ (dimensionless)) is shown in Chart-5. The relation between the discharge $\left(\mathrm{Q}\left(\mathrm{m}^{3} / \mathrm{sec}\right)\right)$ and the heading up losses (HL) over its length (HL/L (dimensionless)) is shown in Chart-6.

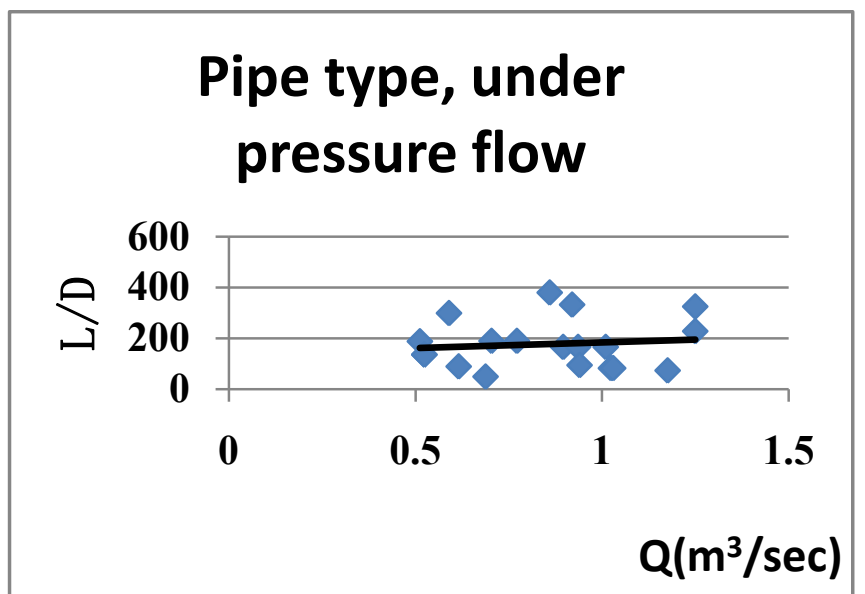

Chart-5: Design Curve of Pipe Type, under Pressure Flow for (L/D)

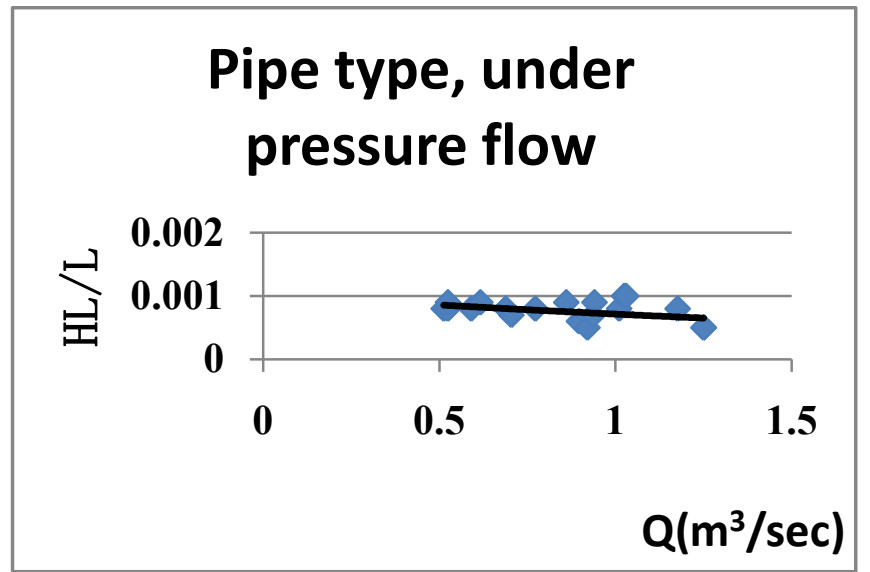

Chart-6: Design Curve of Pipe Type, under Pressure Flow for (HL/L)

\subsubsection{Design Curves for Pipe Type under Gravity} Flow

The relation between the discharge $\left(\mathrm{Q}\left(\mathrm{m}^{3} / \mathrm{sec}\right)\right)$ and the length of covering over its diameter (L/D (dimensionless)) is shown in Chart-7. The relation between the discharge $\left(\mathrm{Q}\left(\mathrm{m}^{3} / \mathrm{sec}\right)\right)$ and the heading up losses (HL) over its length (HL/L (dimensionless)) is shown in Chart-8.

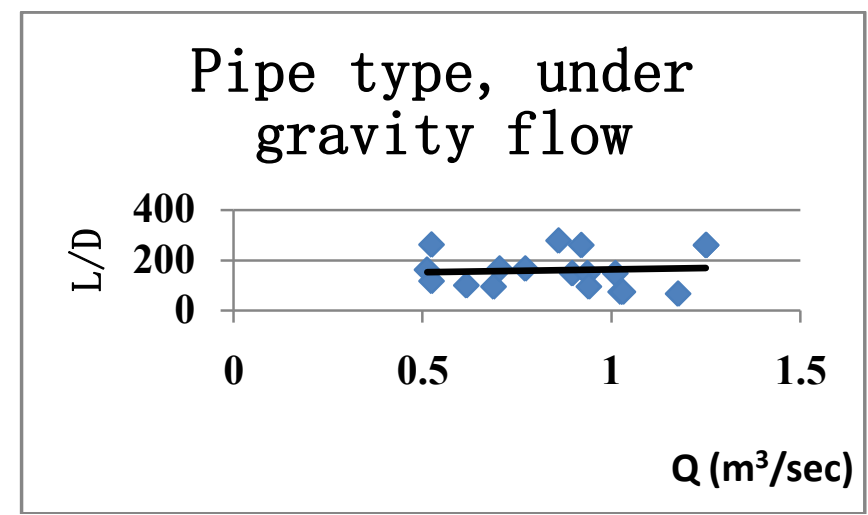

Chart-7: Design Curve of Pipe Type, under Gravity Flow for (L/D)

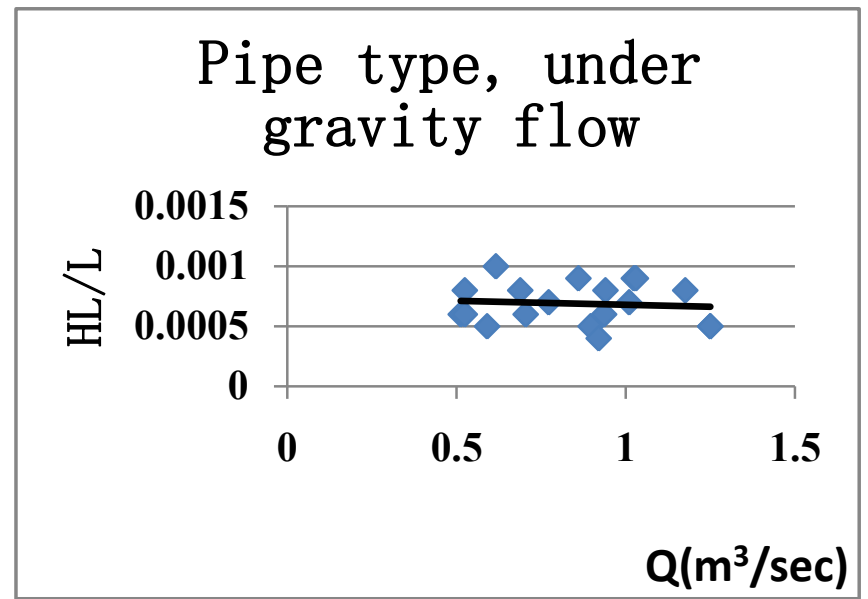

Chart-8: Design Curve of Pipe Type, under Pressure Flow for (HL/L)

\subsection{Economic Results}

The results of economic study are analyzed for the four alternatives which redesigned. However the best alternative in the point of economy is chosen in the two periods (in the past and in year 2013).

\subsubsection{Saving Money for the Redesign in the Past}

1- For drains (from 1 to 16, 19 and 20) it's found that the best alternative in economic point which saves largest value of money is resulted from the case of pipe type, 
under pressure flow. For drains (17and 18) for case of pipe type it's found that the largest value of money saving is resulted from actual covering.

2- The final results of economic analysis are the best choice of covering and the best type of flow for each drain in the past as shown in Chart-9.

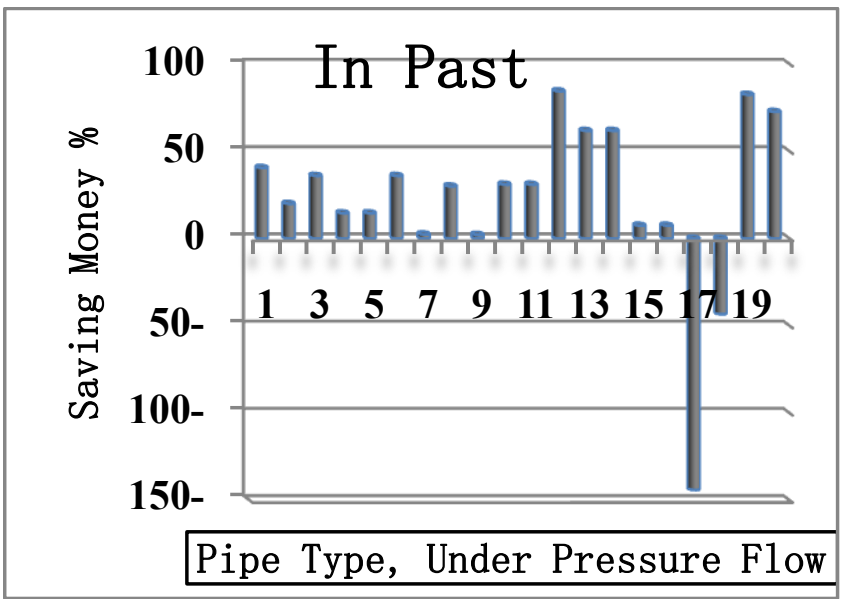

Chart-9: The Percentage of Saving Money in the Past

\subsubsection{Saving Money for the Redesign in Year 2013}

1- For drains (from 1 to 16 and 19), for case of pipe type it's found that the largest value of money saving is resulted case of pipe type, under pressure flow. For drain (20), it's found that the largest value of money saving is resulted cases of pipe type, under pressure or under gravity flow. For drains (17and 18), it's found that the largest value of money saving is resulted from actual covering.

2- The final results of economic analysis are the best choice of covering and the best type of flow for each drain in year 2013 as shown in Chart-10.

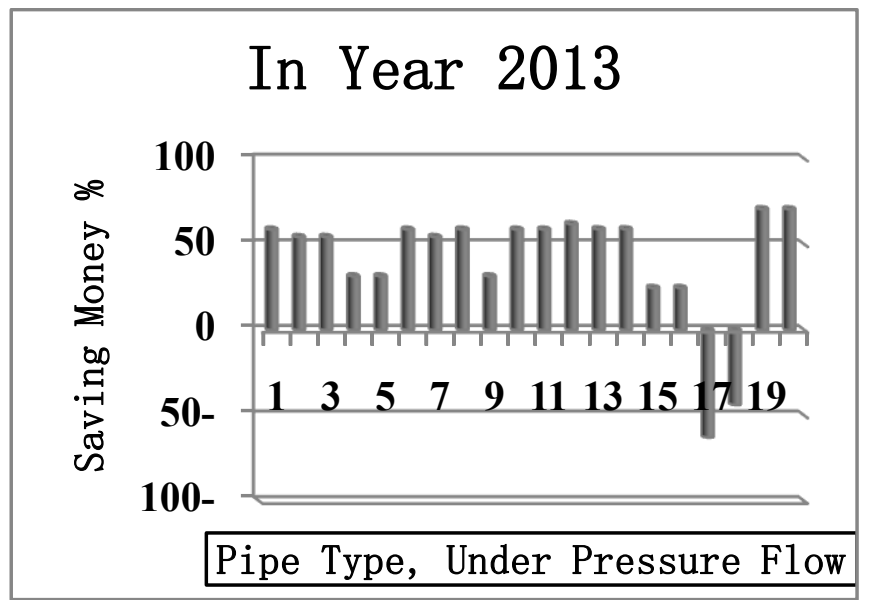

Chart-10: The Percentage of Saving Money in Year 2013

\subsubsection{The Best Choice due to the Hydraulic and the}

\section{Economic Study:}

\subsubsection{In the Past:}

1- For drains (from 1 to 6 , and 8, from 10 to 14,19 and 20), it's found that the best choice is resulted from pipe type and under gravity flow case, because of decreasing in the area section and increasing in the money saving as shown in Chart-11.

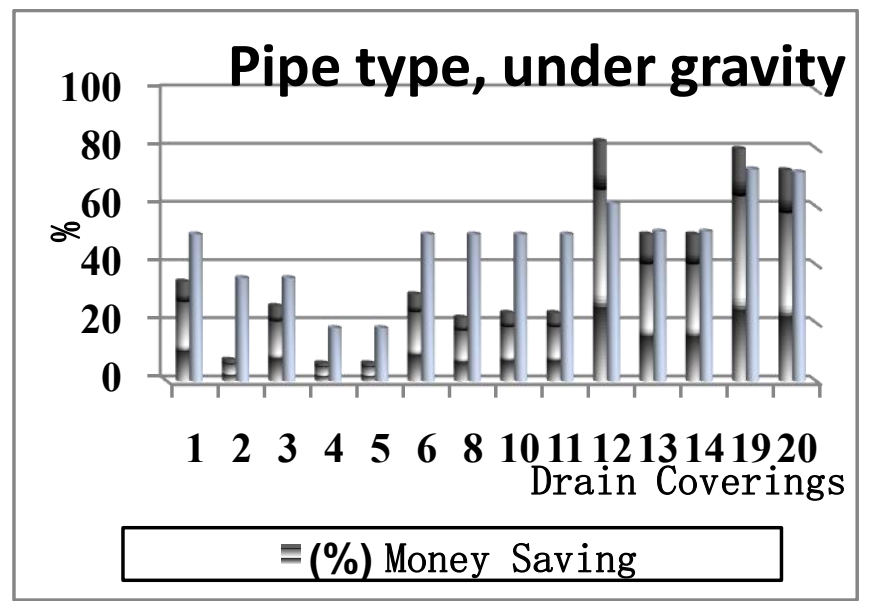

Chart-11: The Percentage of A and Money Saving for Pipe Type, under Pressure Flow, in the Past

2- For drains (7,9, 15 and 16), it's found that the best choice is resulted from pipe type and under pressure flow case, because of decreasing in the area section as well as increasing in the money saving as shown in Chart-12.

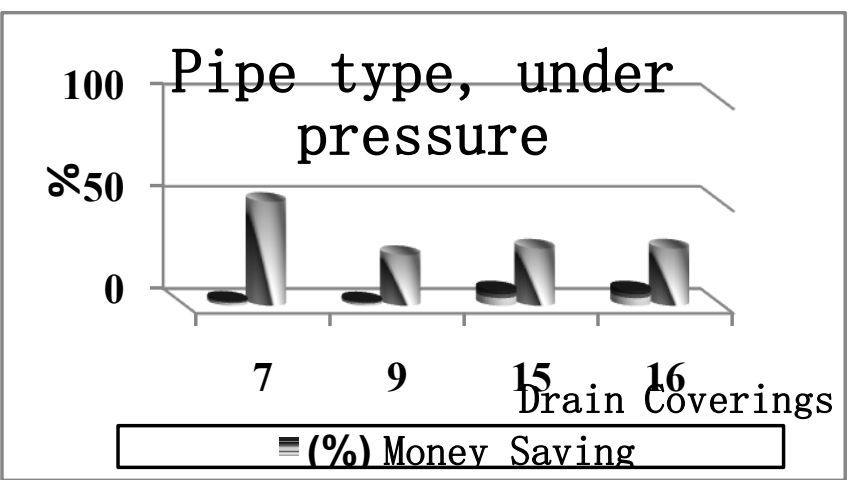

Chart-12: The Percentage of A and Money Saving for Pipe Type, under Gravity Flow, in the Past

3- 3- For drains (17 and 18), it's found that the best choice is resulted from actual design case.

4- 5- From the data of these drain coverings in the past it is found that heading up losses in actual design is very low in actual coverings because of the discharge is low and 
the area is large, but the velocity is not in the range and causes slitting. The design velocity is in the range as well as the slitting and scouring not occurred.

\subsubsection{In Year 2013:}

1- For drains (from 1 to 16,19and 20), it's found that the best choice is resulted from pipe type and under gravity flow case, because of decreasing in the area section and increasing in the money saving as shown in Chart-13.

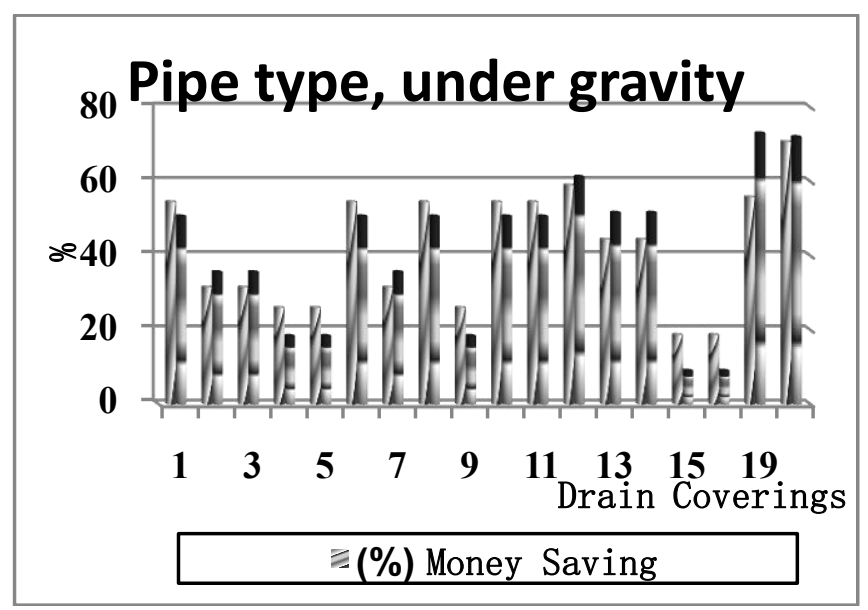

Chart-13: The Percentage of A and Money Saving for Pipe Type, under Gravity Flow, in 2013

2- For drains (17 and 18), it's found that the best choice is resulted from actual design case.

\section{CONCLUSIONS}

The covering is closed canal or industrial type. The main problems which lead to cover a drain are: to minimize the adverse impact of a polluted drain. In this research the twenty drains coverings are selected in El-Sharkia governorate, Egypt. Two evaluations are done of these drains coverings according to hydraulic and economic points. The three alternatives are redesigned as pipe type with under pressure flow, pipe type with under gravity flow and box type with under gravity flow. Hazen-Williams equation is used to design the pipe type with under pressure and under gravity flow alternatives and calculate the heading up. Manning equation is used to design the box type with under gravity flow alternative. The economic study is also done. The best alternative is chosen for each drain covering. The result for hydraulic evaluation, the best choice for drains (from 1 to 18) is pipe type with under gravity flow, but for drains 19 and 20 is pipe with under pressure flow. The result for economic evaluation in the past and in year 2013, it's found that the best alternative is pipe type with under pressure flow for drains (from 1 to 16, 19 and 20), but for drains (17and 18), it's found that the best alternative is resulted from actual covering. The best alternative for both hydraulic and economy evaluations is different for the selected drains coverings. The best choice in the past for drains (from 1 to 6,8 , from 10 t0 14, 19 and 20) is pipe type with under gravity. The best choice for drains $7,9,15$ and 16 is pipe type with under pressure flow. The best choice in year 2013 for drain (from 1 to 16, 19 and 20) is pipe type with under gravity flow. The best choice for drains 17 and 18 is actual design in the past and in year 2013.

\section{REFERENCES}

[1]. Christodoulou "Drop Manholes in Supercritical Pipelines", Journal of Irrigation and Drainage Engineering, 1991 Vol. 117, No.1, pp. 37-47.

[2]. Dasika "New Approach to Design of Culverts", Journal of Irrigation and Drainage Engineering, ASCE, 1995, Vol. 121, No.3, pp. 261-264.

[3]. Clarht and Charles "Experimental Test of a Model for Laminar Slurry Flow with Sedimentation" The Canadian Journal of Chemical Engineering, 1997, Vol. 75.

[4]. Ferro "Applying Hypothesis of Self-Similarity for FlowResistance Law of Small-Diameter Plastic Pipes", Journal of Irrigation and Drainage Engineering, 1997, Vol. 123.

[5]. Hager and Guidice "Generalized Culvert Design Diagram", Journal of Irrigation and Drainage Engineering, 1998, Vol. 124, No.5, pp. 271-274.

[6]. Bombardelli and Garcia "Hydraulic Design of LargeDiameter Pipes", Journal of Hydraulic Engineering, 2003, Vol. 129.

[7]. Brasington and Smart "Close Range Digital Photogrammetric Analysis of Experimental Drainage Basin Evolution", Earth Surface Processes and Landforms, 2003, Vol. 28, pp.231-247

[8]. Lee and Jin "Development of Program for Box Culverts Design", Proceedings of the $35^{\text {th }}$ Conference, Korean Society of Civil Engineers, 2003, pp. 2686-2689.

[9]. Tao and Xiyun "Numerical Simulation of Drop Migration in Channel Flow under Zero-Gravity", Chinese Journal of Mechanics Press, Beijing, China, 2004, Vol. 20, No.3

[10]. American Association of state Highway and Transportation Officials "Model Drainage Manual", 2005, pp. 29-53.

[11]. Wood "Water Hammer Analysis - Essential, Easy and Efficient" Journal of Environmental Engineering, 2005.

[12]. Ku and Jun "Development of Culvert Design Model", Proceedings of Korea Water Resources Association Conference, 2008, pp.645-649.

[13]. Kang, Koo, Chun, Her, Park, and Yoo "Design of Drainage Culverts Considering Critical Storm Duration", Bios-stems Engineering, 2009, Vol. 104 No.3, pp. 425-434.

[14]. Korea Expressway Corporation "Road Design Guideline", 2009, Vol. 2, pp. 494-508.

[15]. Fahmy "Covering of Canals and Drains, Advantages and Disadvantages", Article submitted to a scientific committee of Public Works and Water Resources, 2011. 
[16]. Vatankhah and Easa "Simplified Accurate Solution for Design of Erodible Trapezoidal Channels", Journal of Hydrology Engineering, 2011, Vol. 16, pp.1943-5584

[17]. Colin, Catherine and Fabre, "Turbulent Bubbly Flow in Pipe under Gravity and Microgravity Conditions" Journal of Fluid Mechanics, 2012, Vol. 711, pp. 469-515

[18]. Yoo and Lee "Direct Determination of the Width or the Height for a Box Culvert Applying Dimensionless Equations", KSCE Journal of Civil Engineering, 2012, Vol. 16, No. 7, pp.1302-1307

[19]. Harald Hanche-Olsen "Buckingham's pi-theorem", TMA4195 Mathematical modeling, Version 2004.

[20]. Egyptian Code "Design and Construct Pipe Line for Water and Sanitary Network", 1998, Egypt.

[21]. Egyptian Code for Water Resource and irrigation Works, 2003, Vol. 3, pp. 1-43, Egypt.

[22]. Cook, Bloomquist, Zink, and Ansley "Evaluation of Precast Box Culvert Systems" Final Report No. BC354 RPWO \#47, March 2002.

[23]. Newnan "Engineering Economic Analysis", 2011, $11^{\text {th }}$ Edition, Oxford University, http://summer.yonsei.ac.kr/files/course/Engineering

Economics [1].

\section{BIOGRAPHIES}

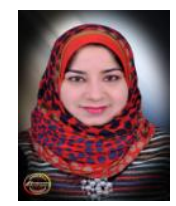

Name: Shaimaa M. Khiry

E-mail:ShaSha533@yahoo.com

Current Position: Civil Engineer in Drainage Projects Organization for East Delta, Ministry of public works and water resources

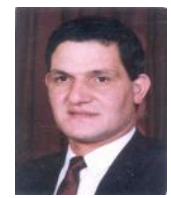

Name: Magdy H. Mowfy

E-mail:magdy_mowfy@yahoo.com

Current Position: Professor of water structures in

Water and water Structures Engineering Department, Faculty of Engineering, Zagazig

University

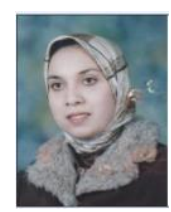

Name: Walaa Y. El-Nashar

E-mail: Walaanashar@yahoo.com

Current Position: Lecture in Water and water Structures Engineering Department, Faculty of Engineering, Zagazig University. 